\title{
Modeling of Thermophysical Phenomena When Cutting with Coated Tools
}

\author{
Marina Volosova ${ }^{1, *}$, Artur Migranov ${ }^{1}$, and Maksim Rai ${ }^{1}$ \\ ${ }^{1}$ Moscow State Technological University "STANKIN", RU-127055, Moscow, Russian Federation
}

\begin{abstract}
The results of computer simulation of thermophysical phenomena in the contact zone during blade cutting of metals with multi-layer composite wear-resistant coatings that ensure the adaptability of the cutting wedge to friction conditions are presented. On-site experimental studies of the cutting temperature during turning with various coatings, structural-phase analysis of the surface layer of the cutting tool to explain the mechanism of formation of secondary structures with a shielding effect - the effect of selforganization.
\end{abstract}

\section{Introduction}

The efficiency of automation of technological processes and the use of modern expensive high-performance machine-tool equipment equipped with mechatronic systems requires a more complete study of the features of the temperature-force conditions of blade metal cutting, where the weakest link in terms of wear resistance is the cutting tool [1-3]. Currently, considerable experience and theoretical and experimental studies have been accumulated to improve the performance of cutting tools by using modern multilayer composite wear-resistant coatings that are capable of adapting to frictional conditions during cutting by forming protective secondary structures.

It is known [4-8] that cutting is a thermodynamic process, and at the same time thermal phenomena in the contact zone have a significant effect, both on the whole on the state of the cutting wedge and on the structuralphase state of the surface layer of the coated tool, due to the activation and passivation of energy ... A change in the internal energy of the tribosystem further leads to the interaction of the activated surfaces with the environment and the formation of protective structures that serve as a kind of shield between the contacting materials. The contact of a tribopair is carried out using secondary structures formed in the friction zone due to self-organization. The importance of using this phenomenon in engineering and technology is undeniable. During friction and wear, the selforganization of the tribosystem materials occurs as a reaction to external conditions caused by the cutting process, which, in many cases, leads to fundamental structural changes in the surface layers of materials. These changes concern many characteristic properties of rubbing surfaces and nearby surface layers (for example, geometric parameters, microstructure, physicochemical and mechanical properties).
Friction always accompanies wear, it is the only "normal" cause of wear and loss of cutting properties by the tool, and the general patterns of friction and wear of an interacting pair of materials of the tool and the workpiece are a practical basis for determining and assigning cutting conditions. Arising directly in the process of cutting and influencing its phenomena, friction itself depends on the elements of the cutting regime, which create specific conditions for the flow of friction, characterized by high pressures (plastic deformation) in the friction zone, a wide range of temperatures and the presence of third bodies (protective secondary structures) on rubbing surfaces, etc. Based on the foregoing, we can assume the existence of an "ideal" in terms of temperature-force conditions of cutting and wear resistance of the cutting tool model of a cutting wedge, which has the form of a puff cake (composite) (Fig. 1), formed by a complex (combined) impact on the surface layer as a result self-organization. In this case, each layer of the "pie": the application of wear-resistant and damping coatings (layers 1 and 2), the implantation of various metals and non-metals (layer 3 ) and the use of lubricating and cooling technological means (COTS) as a catalyst, is responsible for a certain zone of the wear curve and improves the wear resistance of the tool as a whole.

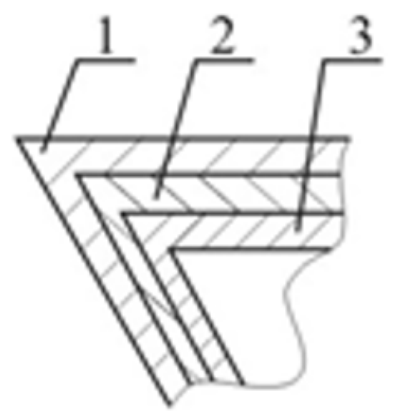

Fig. 1. Cutting wedge model

Corresponding author: m.volosova@stankin.ru 
The aim of the work is to simulate thermophysical processes and phenomena of self-organization during blade cutting with a tool with composite coatings that minimize the intensity of wear of the cutting tool under various temperature and force conditions in the contact zone.

\section{Materials and methods}

In this work, a series of full-scale experiments in longitudinal turning and milling were carried out to study the tribotechnical characteristics and wear resistance of cutting tools with different coatings in terms of composition and atomic structure of the surface layer of the material. At the same time, the analysis of the literature data showed that in the presence of numerous works [2-5] on the study of contact processes when working with a cutting tool covered with a multilayer composite wear-resistant coating, there are no data on the study of the effect of the use of cooling lubricants and the coatings themselves that have the effect self-organization during friction and the formed protective secondary structures on the contacting surfaces on the distribution of heat fluxes from the cutting zone and control of temperature and power conditions during cutting, by varying the physicomechanical, thermophysical, physicochemical parameters of media and coatings. The above problem can be modeled in the presence of a large number of applied software products for personal computers by using them to significantly reduce the labor intensity, high cost of field experiments and increase the multivariance of solutions.

When considering the contact "tool - part", the heat flux from the cutting zone is distributed between the workpiece, the cutting tool, coming off the chips and the environment [2]. At the same time, with a directed change in the physicomechanical, structural and thermochemical properties of lubricating-cooling technological means and multicomponent composite coatings, it is possible to have a significant effect on the direction and, in general, on the distribution of the heat flow. With an increase in the heat flux transferred to the chips (under conditions of high-speed processing), the thermal loading of the cutting wedge of the tool decreases, followed by a change in adhesive and diffusion wear. Heat removal (recovery) in the cutting zone at low processing speeds provides a lubricating effect due to the formation of rutile from the coatings and leads to a decrease in abrasive wear.

On the basis of well-known works [2,6] to solve the equation of thermal conductivity and thermophysical parameters in relation to the tool with a coating, systems of differential equations were compiled for each of the sources, followed by the development of a program for their calculations and calculations of temperature fields in the cutting zone were carried out. The calculation results and analysis of the obtained multivariate data showed that, firstly, it is always necessary to take into account the variability of the main components of the equation, secondly, it is impossible to systematize them, and thirdly, it is impossible to give a visual assessment of the temperature field in the cutting zone, which allows regulating the cutting conditions.

Currently, to solve such complex problems and the possibility of assessing the direction and amount of heat flux, the software packages DEFORM, ANSYS and other various versions are increasingly used in engineering and research in thermophysical analysis. This makes it possible to carry out not only modeling, but also to clearly demonstrate the direction of the heat flow at different cutting speeds and to illustrate the contact processes in the cutting zone at different thermophysical properties of multilayer wear-resistant coatings and variability of technological parameters.

In this work, a series of full-scale tests were carried out to determine the tribotechnical characteristics of carbide cutting tools of the VK, TK and TTK groups with various coatings (TiCr)N, ( $\mathrm{TiAl}) \mathrm{N}, \quad(\mathrm{AlTi}) \mathrm{N}$, (TiAlCr)N, (AlTiCr)N, as well as by determining the cutting temperature by the natural thermocouple method when turning $40 \mathrm{X}$ structural steel with a hardness of 20 HRC on a 16K20 screw-cutting lathe with non-regrowth plates with all of the above coatings. At the same time, preliminary experimental studies and comparative analysis of the data of the mathematical model with the real values of the cutting temperature and wear resistance of the cutting tool applied by various companies (Balzers, Caromant, Carbide, Rimet) were carried out using factory technologies.

The tribological properties were determined using a specially designed adhesion meter [9]. The adhesive meter in Fig. 2, a rotating indenter with investigated coatings 2 was placed between two polished specimens 1 made of the material being processed. To simulate friction conditions similar to the cutting process, the samples and the indenter were heated by an electrocontact method in the temperature range from 150 to $1050^{\circ} \mathrm{C}$. To create plastic deformation in the contact zone, similar to the cutting process, samples from the processed material 1 were compressed by a force equal to $2400 \mathrm{~N}$. In this case, the adhesive component of the friction coefficient was used to assess the antifriction properties of the layer. This component is important for assessing and predicting the intensity of wear during metal friction. It was defined as the ratio of the shear resistance $\tau_{n n}$ caused by the adhesive interaction between the materials of the tool and the workpiece to the normal stress $P_{r n}$ arising at the plastic contact at test temperatures $\left(\tau_{n n} / P_{r n}\right)$.

In this work, to obtain information about the average contact temperature during cutting with a sufficiently high accuracy, simplicity and reliability, according to the recommendations of [2, 10-13], the natural thermocouple method was used, a schematic diagram of which for turning operations is shown in Fig. 3. To exclude measurement errors from "stray parasitic" thermoelectromotive forces, the part and the cutter were isolated from each other with textolite gaskets [14-16]. 


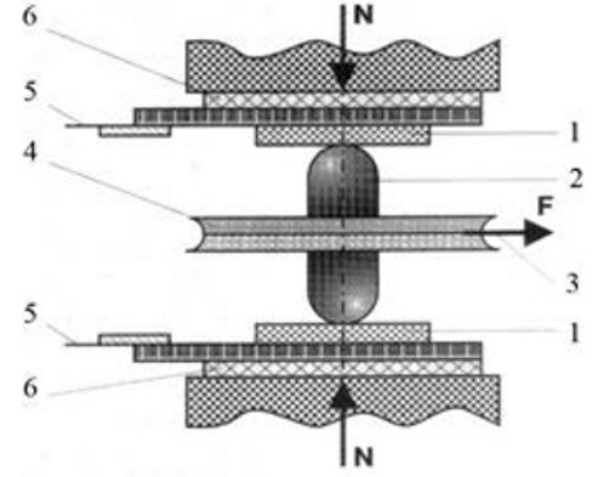

Fig. 2. Model of the setup for the study of tribotechnical properties

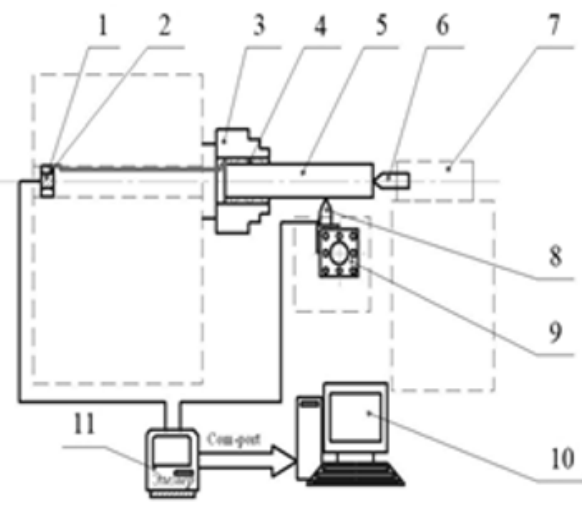

Fig. 2. Scheme of temperature measurement by natural thermocouple method. 1 - mercury current collector; 2, 4 - insulation; 3 - cartridge; 5 - blank; 6 - isolated back center; 7 - tailstock; 8 - tool holder; 9 - cutter with insulation; 10 - computer; 11 - digital voltmeter

The results of temperature experiments when turning with a cutting tool with different coatings are shown in Fig. 3. It was found that the most favorable from the point of view of temperature (thermal loading) of the cutting zone while minimizing the wear rate of the cutting tool is a multilayer composite coating (TiAl)N from Rimet [17-24].

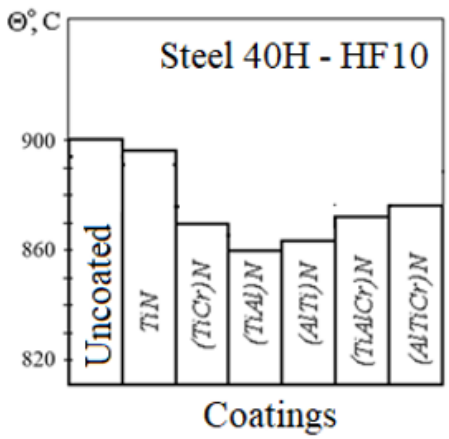

Fig. 3. Effect of coating type on temperature in the cutting zone during longitudinal turning

\section{Results of the study}

When developing the methodology and modeling, the following assumptions were made: thermal conductivity, specific heat of the tool and processed materials do not depend on temperature: sources of heat generation are distributed in the contact surfaces and in the shear plane; the cleavage plane is perpendicular to the front surface of the cutter; there is no heat exchange with the environment; friction coefficients, cutting forces, chip shrinkage coefficient, length of contact surfaces for cutting tools with different coatings are variable; the speed of movement of the elements of the chip material is the same along its thickness. The values of the intensity of heat release were taken from the works of Professor A.N. Reznikov. To ensure the identity of the experimental data and the simulation results, the constancy of the optimal cutting speed in terms of the intensity of the cutting tool wear was ensured with the variability of the thermal conductivity coefficient and the physicochemical composition of the coatings. In fig. 4 shows the results of calculations in the ANSYS software package for various thermal conductivity coefficients of the material of the part, tool and coating.

Based on the results of field experimental studies and modeling, it was found that the coating material is involved in direct contact with the part, the thermal conductivity of which varies depending on the type of coating. So, in Figure 4a, the thermal conductivity of the coating $\lambda=0.25$, in Figure $4 \mathrm{~b} \lambda=0.15$. In this case, the temperature in the chips increases as the thermal conductivity of the coating changes at the same contact temperature, i.e. most of the heat from the cutting zone is transferred to the chips. Thus, by changing the thermophysical properties of the friction surfaces, the thickness and structural composition of coatings for cutting tools, it is possible to predict and control the thermal regime, thereby minimizing the intensity of wear of the cutting tool/

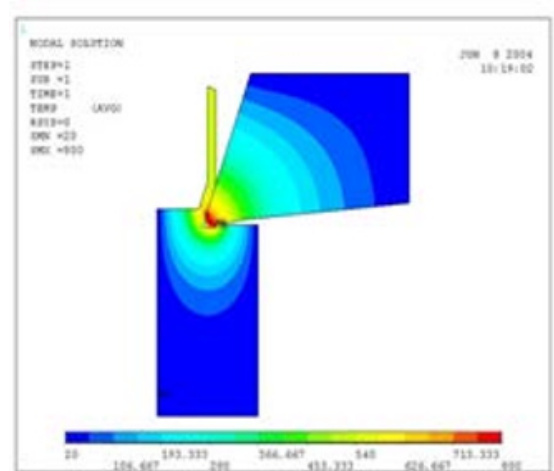

a)

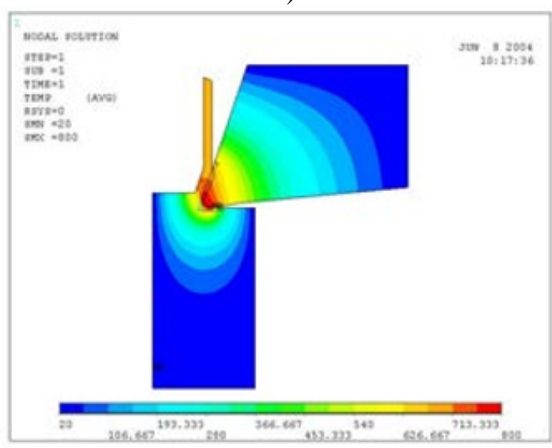

b)

Fig. 4. Calculation of temperature fields in the ANSYS environment: $\lambda=0.25$ (a); $\lambda=0.15$ 
Interesting results from the point of view of clarity and information content were obtained using the DEFORM software package (Fig. 5-7). In particular, you can see Fig. 5, that at the beginning of cutting with a multilayer coating (step 733), the bulk of the heat is concentrated on the rear surface of the cutting wedge, while due to the high temperature in the cutting zone and adhesion phenomena, the radial wear of the cutting wedge will intensify, which determines the size of the workpiece and the quality indicators of the surface layer. At the same time, after some time in Fig. 7 (step 1294), a redistribution (transition) of the heat flux from the rear to the front surface of the tool occurs, i.e. most of the heat goes into the chips, which is more favorable from the point of view of adhesion and reduction of dimensional wear [2,3]. Modeling in this environment allows, in addition to thermophysical parameters, to take into account technological parameters - cutting speed, the presence of a coating or coolant, as well as the wear of the cutting tool and their effect on the distribution of heat fluxes, which is important when using this technique in real machine-building production.

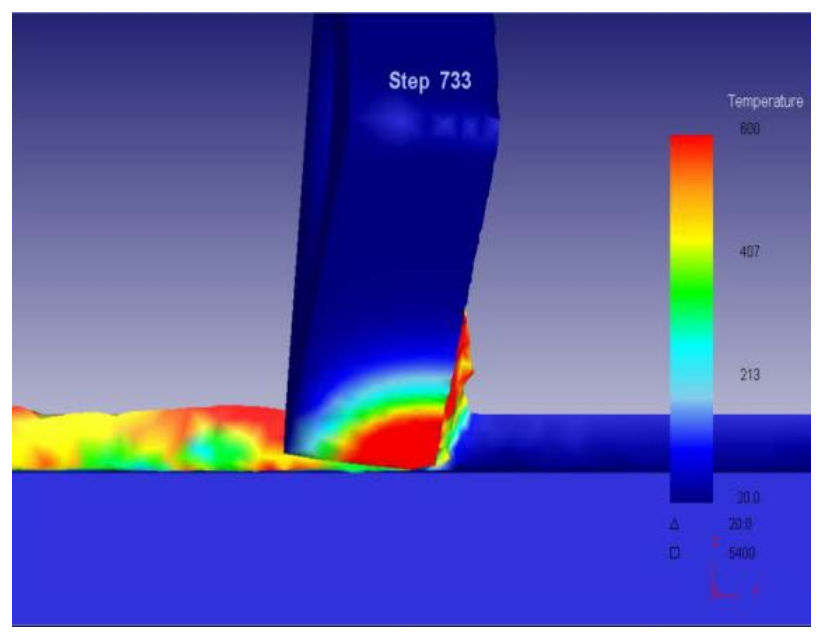

Fig. 5. The picture of thermal phenomena in the contact zone of the cutting coated tool at cutting speed $V=450 \mathrm{~m} / \mathrm{min}$

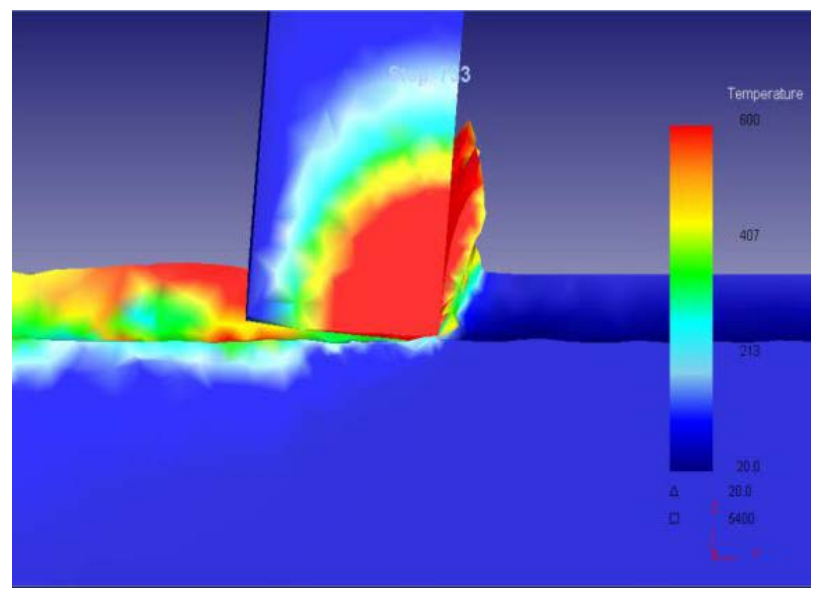

Fig. 6. The picture of thermal phenomena in the contact zone of the cutting uncoated tool at cutting speed $V=450 \mathrm{~m} / \mathrm{min}$

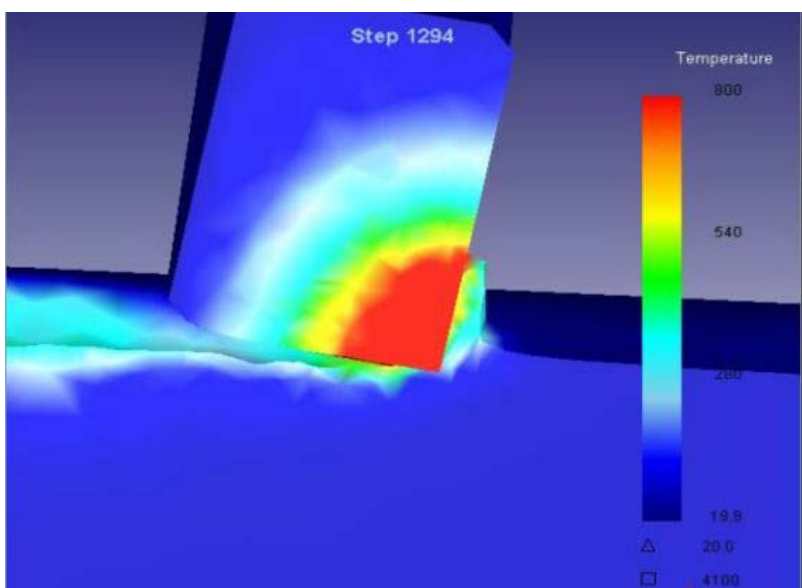

Fig. 7. The picture of thermal phenomena in the contact zone of the cutting coated tool at cutting speed $V=450 \mathrm{~m} / \mathrm{min}$ (after 5 minutes and at $h_{3}=0.15 \mathrm{~mm}$ )

Comparative analysis of the results of calculating the values of temperatures by mathematical models and data from field experiments showed that the discrepancy is $3 \ldots 6 \%$ and is a fairly objective assessment of the temperature field in the cutting zone [6]. On the basis of theoretical and experimental studies, recommendations on the temperature regime are proposed to ensure the minimization of the intensity of wear of cutting tools with various coatings.

To explain the mechanism of changing the temperature regime and heat flux in the contact zone, additional studies of the surfaces of the cutting tool with coatings after cutting were carried out [7, 8]. To understand the physical mechanism of the phenomena that take place on the surface "cutting tool - workpiece", the chemical and phase compositions of the surface layers were studied using modern techniques and equipment to analyze the composition of the coating surface and the outer surface of the films formed on the edge of the cutting tool, as well as for analyzing the contacting surface of the chips. For these studies, various special samples and oblique sections were made.

The results of spectroscopic studies made it possible to establish that during high-speed cutting, titanium oxides, the so-called rutiles and aluminum oxides with an amorphous structure, are formed on the surface of the coated cutting tool. It is known [1,4,7] that rutiles work as a lubricant, while amorphous-like structures have shielding (for heat flux) and protective (wear-resistant) effects.

\section{Conclusion}

The results of full-scale experimental studies in turning and computer simulation of thermophysical phenomena when changing the cutting temperature are comparable. In a wide range of changes in the elements of the cutting mode when turning with a cutting tool with wearresistant coatings for preliminary calculations and the development of promising multilayer composite coatings with the effect of self-organization, one can use the software products DEFORM and ANSYS, and they confirm the adequacy of the model. 
High-speed cutting leads to tribooxidation of multilayer composite coatings, which is an important and favorable process for the phenomenon of selforganization and the formation of oxygen-containing compounds on a metal basis, which can act as a shield and protect the tool surface and generally increase wear resistance. In this case, the effect of self-organization makes it possible to create coatings that provide a favorable temperature regime in the contact zone during cutting.

\section{Acknowledgments}

The study was carried out with the financial support of the Russian Foundation for Basic Research within the framework of scientific project No. 21-79-30058. This work was carried out using equipment provided by the Center of Collective Use of MSUT "STANKIN".

\section{References}

1. G. Polzer, V. Ebeling, Firkowski, Friction and wear, 9(1), 12 (1988)

2. A.D. Makarov, Mashinostroenie, 278, (1976)

3. S.A. Vasin, A.S. Vereshchaka, V.S. Kushner, MSTU named after N.E. Bauman, 448, (2001)

4. G.S. Fox-Rabinovich, A.I. Kovalev, L.S. Shuster, Y.F. Bokiy, G.K. Dosbayeva, D.L. Wainstein, V.P. Mishina. Wear, 206(1-2), 214-220 (1997)

5. N.K. Krioni, M.Sh Migranov, Innov. Mash, 377, (2016)

6. M.Sh. Migranov, R.G. Akhmarov, A.M. Migranov, Mekh. fiz. prots. Poverkh, 83-86, (2018)

7. M.Sh. Migranov, R.M. Migranova, Key Engineering Materials, 496, 75-79, (2012)

8. A.S. Vereschaka, M.Sh. Migranov, A.A. Vereschaka, O. Sharipov. ARPN Jour. of Eng. and App. Scie., 10(20), 9282-9286, (2015)

9. Patent RF 34249 for utility model. Pribor dlya issledovaniya adgezionnogo vzaimodeystviya [Device for the study of adhesive interaction] / Shuster L.Sh., Migranov M.Sh. Declared 06/24/2003. Published 11/27/2003, Bulletin No. 33.

10. T.N. Loladze, Strength and wear resistance of the cutting tool (M.: Mashinostroenie, 1982)

11. M. Volosova, S. Grigoriev, A. Metel, A. Shein, Coatings, 8, 287, (2018)

12. Yu.B. Rumer, M.Sh. Ryvkin, Thermodynamics, statistical physics and kinetics (Moscow: Nauka, 1977)

13. I.B. Zolotukhin, Sorosovskiy Educational Journal, 1, 103-106 (1998) [in Russia]

14. Y.G. Kabaldin, D.A. Shatagin, M.S. Anosov, A.M. Kuzmishina Intelligent Control of Technological Systems in Digital Manufacturing, 1(178), 3-12 (2020)

DOI: 10.18698/0536-1044-2020-1-3-12
15. S.N. Grigoriev, O.V. Sobol, V.M. Beresnev, I.V. Serdyuk, A.D. Pogrebnyak, D.A. Kolesnikov, U.S. Nemchenko, J. Frict. Wear, 35(5), 359, (2014)

16. O.V. Sobol', A.A. Andreev, S.N. Grigoriev, V.A. Stolbovoy, Probl. At. Sci. Technol., 4, 174, (2011)

17. M.Sh. Migranov, Friction and lubrication in machines and mechanisms, 5, 23-26 (2015)

18. A.S. Metel, V.P. Bolbukov, M.A. Volosova, S.N. Grigoriev, Yu.A. Melnik, Instrum. Exp. Tech., 57(3), 345, (2014)

19. V.V. Kuzin, S.N. Grigor'ev, M.A. Volosova, Refract. Ind. Ceram., 54, 376, (2014)

20. M.Sh. Migranov, Improving the wear resistance of tools based on the intensification of the processes of adaptation of friction surfaces when cutting metals (Publishing house "Gilem" of the Academy of Sciences of the Republic of Belarus, 2011)

21. S.Y. Zhu, J. Cheng, Z.H. Qiao, J. Yang, Tribology International, 133, 206-223 (2019) DOI: 10.1016/j.triboint.2018.12.037

22. A. Chouhan, T.K. Sarkar, S. Kumari, K.L.N. Sivakumar, H. Sugimura, O.P. Khatri, Applied Surface Science, 538, $148041 \quad$ (2021) DOI: 10.1016/j.apsusc.2020.148041

23. S.M. Aouadi, J.J. Gu, D. Berman, Journal Of Vacuum Science \& Technology A, 38(5), 050802 (2020) DOI: $10.1116 / 6.0000350$

24. K. Yang, J.Q. Zeng, H.S. Huang, J.D. Chen, B.A. Cao, Materials, 12(17),
DOI: $10.3390 / \mathrm{ma12172744}$ \\ $2744 \quad$ (2019)}

